\title{
La Iglesia que surge en el contexto urbano de la ciudad"
}

\section{Andrea Puentes Rodríguez}

Recepción: 15 de julio de 2018 • Aprobación: 11 de agosto de 2018

\section{Resumen}

El deber de conocer el contexto específico en el que cada Iglesia se arraiga es una condición necesaria para la construcción de una acción pastoral y misionera coherente con los distintos cambios que moldean la sociedad actual. En particular modo con referencia al contexto urbano, tal acción debe responder a las exigencias de unidad en la complejidad, de solidaridad y de humanidad. El gran y rápido crecimiento de la ciudad ha hecho, por ejemplo, que la relación Iglesia-ciudad se haya diluido, que la parroquia como la vida religiosa en la ciudad pasara a ocupar un segundo lugar en la vida del ciudadano. El contexto en el que vive la Iglesia urbana, sin duda, influye en su modo de ser y de autocomprenderse, por tanto, tendrá que trabajar en organizar sus estructuras y en construir una praxis pastoral y misionera adecuada.

Palabras clave: misión, ciudad, evangelización, Iglesia, diálogo.

* Artículo producto del proyecto de investigación de la tesis doctoral en misionología, realizada en la Pontificia Universidad Urbaniana, cuyo título es La Iglesia en Bogotá: aspectos eclesiológicos y misionológicos para un discipulado urbano. Citar como: Puentes Rodríguez, A. (2019). La Iglesia que surge en el contexto urbano de la ciudad. Albertus Magnus, X(2), 11-34. DoI: https://doi.org/10.153322/5005413.5211.

** Universidad Santo Tomás, Bogotá, Colombia. Orcid: http://orcid.org/0000-0002-83533704. Correo electrónico: apcieloazul@hotmail.com 


\title{
The Church that emerges in the urban context of the city
}

\begin{abstract}
The duty to know the specific context in which each Church is rooted, is a necessary condition for the construction of a pastoral and missionary action coherent with the different changes that shape the current society. In particular, with reference to the urban context, such action must respond to the demands of unity in complexity, solidarity and humanity. The great and rapid growth of the city, for example, caused the relationship Church - City to be diluted, as the parish as the religious life in the city came to occupy a second place in the life of the citizen. The context in which the urban Church lives, undoubtedly influences and affects its way of being and self-understanding, therefore it will have to work to organize its structures and build an adequate pastoral and missionary praxis.
\end{abstract}

Keywords: mission, city, evangelization, Church, dialogue.

\section{A Igreja que emerge no contexto urbano da cidade}

\section{Resumo}

O dever de conhecer o contexto específico em que cada Igreja está enraizada, é condição necessária para a construção de uma ação pastoral e missionária coerente com as diferentes mudanças que moldam a sociedade atual. Em particular, com referência ao contexto urbano, tal ação deve responder às exigências da unidade na complexidade, da solidariedade e da humanidade. O grande e rápido crescimento da cidade, por exemplo, fez com que a relação Igreja-Cidade se diluiu, que a paroquia como a vida religiosa na cidade passaram a ocupar um segundo lugar na vida do cidadão. O contexto em que vive a Igreja urbana, sem dúvida influencia e afeta seu modo de ser e de autocompreender-se, portanto, terá que trabalhar para organizar suas estruturas e para construir de uma praxe pastoral e missionária adequada.

Palabras-chave: missão, cidade, evangelização, Igreja, diálogo. 


\section{Introducción}

La Iglesia entera es misionera, así es que "incumbe a la Iglesia por mandato divino ir por todo el mundo y anunciar el Evangelio a toda criatura" (Dignitatis humanae, n. 13). Esto incluye la perspectiva de futuro de la misión que está en las ciudades, en particular en las megalópolis del sur del mundo. Para este tipo de misión, serán necesarios métodos y personas nuevas (Ferrari, 2004, p. 7). En el Documento de Puebla, constantemente aparece la preocupación de los obispos por la evangelización de las grandes ciudades latinoamericanas que se encuentran, al menos la mayor parte de ellas, en un proceso de crecimiento, situación que las sitúa entre las megalópolis del mundo. No es extraño que la Iglesia se sienta desorientada y desajustada pastoralmente ante los nuevos fenómenos del urbanismo moderno, como está sucediendo en otras partes del planeta. En efecto, la Iglesia había creado sus fórmulas pastorales para unas ciudades cualificadas por su sedentarismo y emplazadas en áreas casi dominables peatonalmente, que permitían el conocimiento de los ciudadanos entre sí, de tal manera que en la ciudad predominaban las relaciones de vecindad. Por ese motivo, las catedrales, con sus parroquias en las que se centralizaban las organizaciones piadosas y asistenciales, los movimientos apostólicos y la asistencia a los fieles, eran estructuras pastorales suficientes para la evangelización de las ciudades.

La Iglesia está pasando de tener un lugar hegemónico a ser una de tantas organizaciones religiosas, que como sociedad civil debe buscar su espacio y aporte en la reorganización del campo religioso y del servicio social. Ser en este espacio social un "misterio de comunión misionero" exige un discernimiento más atento y dialogante, puesto que las expresiones simbólicas de la misma Iglesia no pueden ser entendidas solo desde su sentido teológico sacramental y litúrgico, sino que deben ser contextualizadas en la compleja red de significaciones que encierra la misma ciudad y de la que los ciudadanos son autores y resultado simultáneamente (Cortés, 2007).

Frente al desafiante futuro, la Iglesia, desde su función y misión evangelizadoras, tiene una responsabilidad excepcional recibidas por mandato de Cristo y la transcendencia de su historia plurisecular en el continente que ha de asumir con fe, con humildad, con valentía y con creatividad (Dorado, 1983, p. 90).

Tres elementos acompañarán entonces esta reflexión: a) la Iglesia y la ciudad: ¿cuál identidad misionera?; b) tal relación y flexión sobre su identidad pasa a través de la figura de la Iglesia local urbana y de reconocer la ciudad como interlocutora de la Iglesia, como ente en relación, participación y diálogo; y c) se 
focaliza en la parroquia en este contexto como el punto neurálgico de la Iglesia local que posibilita lo anterior.

Este breve esquema quiere llamar la atención sobre el tipo de Iglesia que debe emerger en el contexto urbano para una evangelización vivificante y vivificadora.

\section{La Iglesia y la ciudad: ¿cuál identidad misionera?}

Los destinatarios de la acción evangelizadora de la Iglesia, por el hecho de vivir en la gran ciudad, ofrecen posibilidades y dificultades a la difusión del Evangelio. La Iglesia no evangeliza a hombres y mujeres abstractos, sino a personas concretas que se realizan en las condiciones sociales de la gran ciudad, y es desde allí que la Iglesia en la ciudad ha de evangelizar.

La Iglesia ha de hacerse presente en la ciudad tal y como ella es, tal como Cristo la estableció y la sostiene: “Cristo, el único Mediador, instituyó y mantiene continuamente en la tierra a su Iglesia Santa, comunidad de fe, esperanza y caridad, como un todo visible, comunicando mediante ella la verdad y la gracia a todos" (Lumen gentium, n. 8).

Desde el obispo hasta el último de los fieles cristianos han de actuar en la ciudad como miembros de esta unidad comunitaria, visible, que es la Iglesia extendida por toda la tierra. Ha de ser (la Iglesia) en medio de la ciudad signo e instrumento de la unión íntima con Dios y de la unión de los hombres entre sí, en Cristo Jesús. Lo que el Concilio Vaticano II dice a la Iglesia respecto de la familia humana universal es aplicable plenamente a la vida de la Iglesia en la ciudad:

Los gozos y las esperanzas, las tristezas y las angustias de los hombres de nuestro tiempo, sobre todo de los pobres y de los que sufren son a la vez gozos y esperanzas, tristezas y angustias de los discípulos de Cristo. La comunidad cristiana está integrada, por hombres que, reunidos por el Espíritu Santo en su peregrinar hacia el Reino han recibido la buena nueva de la salvación para comunicarla a todos. La Iglesia por ello se siente íntima y realmente solidaria del género humano y de su historia. (Gaudium et spes, n. 1)

La ciudad es la forma organizada del pueblo. Cada pueblo porta consigo elementos para crear las instituciones sociales capaces de asegurar la vida pública y privada de las personas. La primera de estas instituciones es la ciudad como civitas, en cuanto grupo de hombres que viven juntos en forma asociada, y por ello constituyen una ciudad organizada para satisfacer las necesidades humanas, materiales 
y espirituales de cada uno y de la colectividad. Se trata de una relación calificada de lugar de convivencia, de acogida, de intercambio, donde la diversidad se configura como bienes útiles que devienen oferta para el otro, posibilidad de colaboración, porque se pertenece a la misma ciudad y se pertenecen los unos a los otros.

La ciudad conjuga en su interior unidad y pluralidad, convergencia y divergencia, identidad y comunión. Existen tantos barrios pero una sola ciudadanía, distintas clases sociales pero un solo bien común y múltiples servicios pero un solo objetivo: ofrecer a todos los bienes necesarios para vivir. A tantas necesidades sociales corresponden tantas competencias, profesiones, oficinas, puestos, tareas, oficios. La libertad favorece la diversificación de las actividades, de los comportamientos y de los estilos de vida, por lo que permite a cada uno conservar la propia identidad (Marafioti, 2012).

En la sociedad compleja, las ciudades se han convertido en megalópolis donde los barrios aparecerían como ciudades autónomas. La técnica pone a disposición nuevos medios para hacer circular las ideas y llegar al consenso, crear espacios de encuentro y nuevas posibilidades de agregación. El anonimato amenaza cada individuo disperso entre la multitud, empujado hacia la soledad, pero el sentido de pertenencia es el que desarrolla la solidaridad, acerca a las personas y califica las relaciones.

La ciudad es el lugar del nacimiento y de las elecciones. Como lugar de nacimiento, se nos da por los padres, que antes de nosotros han decidido vivir en una determinada ciudad. Como lugar de elecciones, puede ser elegida por cualquiera que decide establecer la propia residencia, atraído por las posibilidades de vida y de trabajo. En este segundo caso, se verifica un encuentro entre el deseo de la persona y la hospitalidad de la ciudad. Nativos y residentes son ciudadanos a igual título, diversos por proveniencia, pero unidos por un amor común por la misma ciudad (Marafioti, 2012).

El fenómeno urbano entonces genera el crecimiento y la expansión de las poblaciones, un nomadismo cotidiano que exige una vida pluriespacial: complejos horarios que originan una población diurna y otra nocturna, una expansión de todo tipo de informaciones y atracciones múltiples para los denominados tiempos de ocio (Dorado, 1983, p. 89).

Muchos de estos elementos pueden ser utilizados para comprender el misterio de la Iglesia, aunque la Iglesia es una "realidad compleja" (Concilio Vaticano II) en la que se conjuga unidad y diversidad, como en la imagen paulina del cuerpo de Cristo, uno en sí mismo y múltiple en sus miembros.

La reflexión sobre la identidad de la Iglesia en la ciudad debe considerar la misión eclesial. Falso sería colocar la pastoral en función de los que van a la Iglesia 
y de los grupos sociales que encuentran su satisfacción en el catolicismo. Por ello, reflexionar sobre el nuevo problema que la metrópoli presenta a la acción evangelizadora y pastoral de la Iglesia no se puede limitar a repetir una definición abstracta sobre ella y sobre el hombre en general, sino que exige determinar cuál es el sentido de ser y de su misión en el nuevo contexto según las características actuales del hombre urbano, repensando, incluso, las estructuras eclesiales esenciales, su validez y adecuación en la metrópolis contemporánea dentro de una teología que se inserta en el designio salvífico-revelador de Dios: "en diálogo con la ciudad debe la Iglesia elaborar una teología de la realidad urbana". Solo en este contexto se puede reflexionar sobre el sentido de la ciudad desde una visión más amplia y sobre la participación cristiana en las tareas que ella tiene, porque solo en un diálogo sincero entre la Iglesia y el hombre metropolitano se podrá formar adecuadamente a los cristianos de hoy para que respondan a su propia vocación y a las urgencias pastorales de la metrópoli (Niño, 1996, pp. 180-181).

Por ello, en la comunidad eclesial, es necesario saber distinguir tantos aspectos distintos como reconocer las recíprocas relaciones entre Iglesia universal e Iglesia local, entre clero y laicado, entre desarrollo de la teología e identidad de la fe; es necesario tener juntos el encuentro con la cultura del tiempo y la transmisión de la tradición, la presencia en la historia y la tensión escatológica, el anuncio del Evangelio y el servicio a los pobres, la búsqueda de interioridad y el compromiso sociopolítico (Marafioti, 2012, p. 234).

Esto exigirá que se asuma la responsabilidad de crear nuevos caminos, diseñar las opciones pastorales que el Espíritu nos inspire y entrar a ser coprotagonistas del momento histórico que se está viviendo.

\section{La Iglesia local urbana}

La Iglesia universal se realiza y expresa en denominadas Iglesias locales (Lumen gentium, n. 23). Sin perder la perspectiva universal de toda la Iglesia, estas tienen como misión inmediata la evangelización del pueblo donde viven colaborando en su salvación integral y comunitaria. Para poder realizar la misión que Dios les ha encomendado, han de asimilar vitalmente el principio teológico-pastoral de que "la evangelización exige la encarnación" (Uribe, 1990, p. 65). Por dicho principio la Iglesia local ha de ser una Iglesia inculturada e integrada, ha de ser también una Iglesia sumergida en la corriente histórica, de tal manera que el pueblo pueda reconocerla como una realidad que le pertenece, manteniendo la fidelidad a Cristo y la fidelidad al pueblo (Dorado, 1983, p. 92). 
La Iglesia local urbana se entiende como la comunidad católica, estructurada y carismáticamente dotada, enraizada en la ciudad y que tiene como misión la evangelización, conversión y salvación de la comunidad ciudadana. La Iglesia local urbana no significa parte o división eclesiástica, más bien describe a aquellos que hacen experiencia de ser Pueblo de Dios en cada ciudad, como se evidencia en cada una de las cartas de Pablo. Para él la Iglesia no se encuentra segregada en un gueto sino radicada en la unidad urbana en la que se encuentra y vive (Tonna, 1978, pp. 215-216). La Iglesia local urbana se correlaciona con la Iglesia universal, cuya misión se delinea de la convergencia de elementos comunes y de aspectos específicos que dependen en última instancia de su relación con la ciudad. Esta relación, como lo recuerda Frosini, no va formulada respecto de la identificación o separación, sino más bien respecto de la distinción y complementariedad; distinguir para unir (Frosini, 2007, p. 257).

Acerca de los elementos comunes, debe, sobre todo, mencionarse el hecho de que la Iglesia es el nuevo Pueblo de Dios que tiene la misión evangelizadora de Jesucristo: fiel al proyecto de Dios Padre, colabora con la fuerza del Espíritu Santo en la salvación integral de la humanidad, mediante un método original y propio - el método del Reino de Dios proclamado en el Evangelio - que pretende alcanzar dicha salvación por la conversión interna de las personas, de las culturas y de los pueblos. La Iglesia, en su misión de salvación, no pretende realizarla por caminos de fuerza e imposición, sino por la conversión interna y profunda que ha de originarse en el mismo corazón de los pueblos y de las culturas (Dorado, 1983, p. 91).

En el conjunto de sus acciones pastorales, la Iglesia ha de mostrar que no vive para sí misma, sino que su misión - en unión con Cristo - es el servicio al hombre. Según la expresión de Pablo VI y de Juan Pablo II, la Iglesia debe ser como el Buen Samaritano del hombre de hoy, debe descubrir en los hombres y en las mujeres de nuestro tiempo los semina Verbi, las semillas que el Verbo de Dios ha sembrado en el corazón de los hombres para cultivarlas y hacer que maduren. En su discurso en el VI Simposio del Consejo de las Conferencias Episcopales de Europa, Juan Pablo II (1985) afirmó:

La Iglesia está llamada a dar un alma a la sociedad moderna [...], debe infundir esta alma no desde arriba y desde afuera, sino pasando dentro, acercándose al hombre de hoy. Se impone pues la presencia activa y la participación intensa en la vida del hombre. El servicio que la Iglesia está llamada a hacer a los hombres y a la sociedad consiste ante todo en ayudarles a creer en el Dios vivo, en Dios Padre que hoy y siempre nos salva por medio de Jesucristo en el Espíritu Santo. 
La realización de esta misión eclesial de servicio exige anteponer tres principios: "la Iglesia debe ser una presencia de comunidad, debe estar siempre en actitud de diálogo y debe constituir una constante presencia de servicio" (Caramurú, 1967, p. 176). Su seguimiento permitirá una verdadera presencia de la Iglesia en la ciudad y la realización de su ser signo evangelizador. La presencia de la Iglesia y de lo cristiano en la ciudad exige no solo una adaptación metodológica y en el mismo contenido, sino que requiere también una espiritualidad urbana que acentúe ciertos rasgos del Evangelio (Niño, 1996, p. 184).

La presencia de la comunidad emana de la acción del Espíritu Santo, que hace a la Iglesia renovarse como instrumento de unión de Dios con los hombres y de transformación de la comunidad, y como sacramento de unidad del género humano. La Iglesia se reconoce como Pueblo de Dios peregrino y misionero, debe amar y conocer al hombre urbano y sus valores, y participar íntimamente de la totalidad y pluralidad de la vida urbana, para poder ser verdaderamente presencia inspiradora de la ciudad de Dios, verdadera "alma" de la vida humana de la ciudad (Niño, 1996, p. 182).

La presencia de la comunidad eclesial será necesariamente presencia de diálogo perenne, para favorecer el encuentro de los hombres entre sí y con Dios. Dicho diálogo presupone, en primer lugar, la libertad de pensar y de hablar sobre la propia Iglesia, sobre el hombre y sobre la ciudad, y en segundo lugar, la insustituible actuación del laicado. Efectivamente, al respecto Caramurú manifiesta:

La presencia de diálogo de la Iglesia en la ciudad estará mejor ejercida por el cristiano competente en tareas temporales. Se requiere de manera especial una presencia de técnicos cristianos en el estudio y en la solución de problemas del urbanismo. Una inspiración cristiana de una mística de urbanización y desenvolvimiento debe ser el resultado del diálogo de la Iglesia en la ciudad. (1967, p. 177)

Asimismo, señala que en los diversos organismos de la ciudad se encuentran católicos que pueden ser la base del diálogo si se provoca el encuentro, y se los llama con el auténtico deseo de aprender primero de ellos (Caramurú, 1967, p. 186).

Finalmente, se trata de una presencia de servicio, que comienza por las mismas estructuras eclesiales; se deben abandonar los esquemas de la Iglesia de cristiandad para pasar a ejercer el papel de sal de la tierra y fermento en la masa, cuya única finalidad es el bien de la comunidad (Niño, 1996, p. 183). Al respecto, Caramurú afirma:

La Iglesia está presente en la ciudad para servir y no para ser servida. Ahora en la misma Iglesia, las estructuras de servicio, como actualmente 
existen, manifiestan más al hombre urbano la intención de dominar que de servir. Es por esto necesario que el pueblo de Dios no se presente en la ciudad como servidor de un grupo, sino como aquel para quien servir es reinar. Está al servicio de la ciudad. No busca su interés propio, sino la salvación de la ciudad. (1967, p. 178)

Evangelizar constituye, en efecto, la dicha y la vocación propia de la Iglesia, su identidad más profunda. Para construir la misión evangelizadora de Jesús, la Iglesia debe llegar a ser cada vez más "Iglesia de los pobres", según la sugestiva expresión de Juan XXIII y de Juan Pablo II (1981, n. 8):

Para realizar la justicia social de las diversas partes del mundo, en los distintos países, y en las relaciones entre ellos, son siempre necesarios nuevos movimientos de solidaridad, la Iglesia está vivamente comprometida en esta causa, porque la considera como su misión, su servicio, como verificación de su fidelidad a Cristo para poder ser verdaderamente la "Iglesia de los pobres". (Peresso, 2007, p. 6)

El progresivo descubrimiento eclesial del mundo de los pobres, de sus anhelos y de sus prácticas, y de las interpelaciones que su situación pone a la fe impulsaron - y siguen haciéndolo-un movimiento de la Iglesia hacia "las orillas" de las ciudades; este "éxodo eclesial hacia los pobres" es el espacio fundamental del momento contemplativo como experiencia de Dios en el pobre y de indignación ética hacia su situación. El éxodo eclesial hacia los pobres - que espacialmente significa el desplazamiento hacia la periferia urbana - y la asunción eclesial del mundo de los pobres y de su espacialidad van progresivamente madurando el contenido teológico de lo que luego se formulará como la "opción preferencial por los pobres" (Martinic, 1993, pp. 76-77).

Dichos elementos comunes configuran también la misión de la Iglesia local urbana, junto a aspectos específicos. El primero de ellos puede indicarse en la inculturación urbana como dato característico de la Iglesia local para tal contexto. La Iglesia local urbana se caracterizará por su inculturación, lo que implica su sintonía con el ethos propio, la asimilación y adaptación al complejo sistema de vida ciudadana, y su ubicación precisa en la ciudad en el conjunto de funciones que se orientan a la promoción del bien de los ciudadanos y de la comunidad urbana (Martinic, 1993, p. 94).

Otra nota de la inculturación urbana es la adaptación de la Iglesia al complejo sistema de vida ciudadana. En efecto, dada la misión evangelizadora de la Iglesia, en su organización y servicio, debe acomodarse, manteniendo la integridad 
del Evangelio, a las posibilidades y a los modos de ser del hombre ciudadano, a su ritmo de vida y a sus diversas organizaciones, lo que supone en la Iglesia un desarrollo de su capacidad creadora y una gran flexibilidad en sus estrategias misioneras pastorales y en la aplicación de sus propias leyes eclesiásticas.

Por último, la inculturación de la Iglesia en la ciudad exige que esta descubra con exactitud y viva el lugar que le corresponde en la ciudad, en el conjunto de las funciones ciudadanas, que han de mantener con respecto a la Iglesia la legítima independencia y autonomía que son propias de las realidades temporales.

El segundo aspecto corresponde a los espacios propios del ejercicio de tal misión. Según la enseñanza de Gaudium et Spes, "la misión propia que Cristo confió a su Iglesia no pertenece al orden político, económico o social: el fin que le asignó es de orden religioso" (n. 42). La Iglesia se sitúa entonces tanto en la sociedad como en la ciudad, entre las estructuras y organizaciones, respetando las autoridades políticas de la ciudad, sumergiéndose en el campo modesto de los ciudadanos, de la humanidad, que legítimamente postulan la libertad para asociarse en intereses comunes - en este caso religioso - y para colaborar desde su originalidad e iniciativa en el mejoramiento de la comunidad ciudadana.

El tercero consiste en los modelos específicos del ejercicio de la misión en la ciudad. Las Iglesias locales urbanas deben crear una relación pastoral original con la ciudad, que, aunque se considere mayoritariamente cristiana, tiene necesidad primordial de ser evangelizada como comunidad urbana. Esta evangelización ha de realizarla desde lo característico de su propia misión. Esa evangelización tendrá que llevarse a cabo con patrones y modelos que respondan al ser y a la manera de actuar, características del hombre y de la comunidad urbana. Ha de ser una evangelización que, al mismo tiempo que atiende al desarrollo de la fe, tiene presente la humanización de la comunidad ciudadana en cuanto tal (Consejo Episcopal Latinoamericano [Celam], 1982, p. 18).

En tales aspectos específicos de la misión de la Iglesia local urbana, encuentra una particular actuación la relación entre la Iglesia y la ciudad, a propósito de la que se pueden introducir otros elementos, poniendo a prueba la reciprocidad, la dinamicidad y las consiguientes aplicaciones.

El hombre no obra siguiendo un proyecto ya preparado desde el inicio y que solo necesite ser puesto en acción. La acción es más bien un proceso, una vía por recorrer. Es solo caminando que se podrán reconocer los pasos que se deben cumplir para alcanzar el final que se anhela. Como el hombre, la Iglesia no se encuentra nunca en perfecta belleza y preparación, ella deviene, mientras con su propia acción se realiza y se adentra en el futuro; por ello, también la Iglesia se encuentra siempre en devenir, se edifica actuando en modo nuevo para 
cada generación, en cada nueva cultura, en cada nueva situación. El tema de esta visión es una doctrina situacional y contextual de la "eclesiogénesis", del nacimiento de la Iglesia, nacimiento en el que se identifica con su praxis y acción. Actuando situacionalmente, la Iglesia local urbana, en este caso, renacerá día a día para cada generación (Zulehner, 1992, pp. 32-33).

En un mundo que se globaliza y urbaniza a la vez, el proceso por el que la Iglesia podría redescubrir su catolicidad estaría en descubrir una praxis pastoral en contexto (Davey, 2001, p. 152). La catolicidad permite a la Iglesia ofrecer un paradigma alternativo a las tendencias de la globalización a la homogeneización, a los desequilibrios de poder y a la exclusión. Al mismo tiempo, convendría aprovecharse de algunos aspectos de la globalización, para ampliar la capacidad de la Iglesia de ser católica de verdad, particularmente en medio de los flujos transnacionales de la vida urbana contemporánea.

Lo mismo que la Iglesia local puede experimentar la contestación y la necesidad de promover una cuidadosa negociación en su vida comunitaria, así también la Iglesia en su nivel global se encontrará con que las culturas, las capacidades y los intereses chocan y se conectan en varios planos (Davey, 2001, pp. 151-152).

La vida local de la Iglesia no puede existir aislada, ya que ella es la presencia vital que permite el compromiso con la realidad de las vidas y luchas de las personas y las comunidades:

La catolicidad de la Iglesia es su poder para encarnarse, sin perder su identidad, en las culturas más diversas. Ser católico no es simplemente expandir el sistema eclesiástico, sino vivir y testimoniar la misma fe en Jesucristo, salvador y liberador, dentro de una cultura particular. (Davey, 2001, p. 153)

Conviene preguntarse en qué sentido vivir en la ciudad condiciona la vida de los discípulos del Señor y de quienes están llamados a serlo incorporándose a la comunidad mediante la acción evangelizadora de la Iglesia. Hay que preguntarse también en qué medida la acción evangelizadora de quienes constituyen la Iglesia, desde el obispo hasta el último de los fieles, está condicionada por el hecho de realizarse en un medio urbano de grandes proporciones (Álvarez, 1988, p. 28).

Se abriría entonces un interrogante: ¿cuál es la misión de la ciudad donde se viven plurales relaciones, mentalidades, culturas, sensibilidades religiosas, lenguajes, espacios, donde confluye continuamente una gran concentración humana viviendo nuevas modalidades de comportamiento y de estilos de vida?

Si los hombres construyen ciudades, no es solo para habitarlas, sino porque están movidos por una idea, por un sueño, por un impulso (Niño, 1996, p. 197). La 
ciudad en contexto cristiano se manifiesta como una totalidad humana con una misión específica y con una legítima autonomía, y constituye a la vez el otro polo de la existencia creyente. En efecto, es necesario reconocer que no basta que Cristo haya venido para que las ciudades se hayan transformado en comunidades verdaderamente humanas, y que, aunque es difícil demostrarlo históricamente, es perceptible un cambio cualitativo en las ciudades gracias a la acción de los cristianos. La salvación de la corrupción de la ciudad no se proyecta solo en el futuro, sino que se trata de una salvación presente, en cuanto a través del Evangelio la ciudad se puede convertir en un verdadero espacio de comunión humana y en cuanto los cristianos, extranjeros por su pertenencia a la Jerusalén futura pero ciudadanos en pleno derecho por su pertenencia existencial, tienen la responsabilidad de transformar sus ciudades y de llevarlas a la realización de su vocación original (p. 209).

En virtud de su vocación y su destino, la ciudad es el lugar de relaciones humanas. Su vocación es acercar a las personas y multiplicar facilidades para los diálogos, los intercambios, los debates y las discusiones. La ciudad debe facilitar las deliberaciones y la participación del mayor número posible de ciudadanos en el mayor número posible de asuntos. La ciudad es el soporte material de la relación humana y debe ser hecha para facilitar todas las relaciones humanas; por eso, la calle y la plaza son tan importantes. En la calle, las personas se encuentran, encuentran un comercio de calle, encuentran a sus vecinos y a personas desconocidas, encuentran conocidos, forman amistades, se comunican. Jamás los encuentros virtuales por la red electrónica podrán reemplazar el contacto directo (Medina, 2011, p. 40).

El urbanismo del siglo $\mathrm{XX}$, en sus progresivas autocomprensiones y tentativas, ha logrado proponer modelos alternativos a las concepciones de los siglos precedentes, al reflexionar sobre la utilidad de la ciudad y al tratar de describirla en términos funcionales; los urbanistas han redescubierto la ciudad como relación entre el hombre y la naturaleza, haciendo explícitas las exigencias que de ello derivan y las funciones humanas a las que la ciudad debe responder para realizar su natural vocación humanizante y salvífica. En este contexto, se puede considerar que "la ciudad es, en último análisis, la encarnación de aquello que la tradición teológica medieval llamaba el bien común" (Niño, 1996, p. 222), fundada en la autonomía de las personas. Según Comblin (1968), el hombre se perfecciona superando su bien particular y participando en una obra común. "Este bien común no es una cosa situada fuera del hombre o más allá del hombre. Es el bien de la comunidad humana. Pues la persona no se desarrolla si no es una comunidad"; y si la comunidad de los hombres es la ciudad, el bien común es la ciudad (citado por Niño, 1996, p. 222). 
Puede afirmarse que la ciudad no existe solo para satisfacer las necesidades materiales de los individuos, sino para satisfacer la necesidad primordial de vivir en común (Ruiz, 2012, pp. 248-249). Se exige, por tanto, asumir una nueva actitud, amigable y comprensiva, si se quieren descubrir los más profundos valores de una ciudad que solo es tal en la medida en que desarrolla la vida social y constituye verdadera comunidad (Niño, 1996, pp. 221-223).

Se puede entonces indicar que la Iglesia tiene la función de aportar y testimoniar en las ciudades aquello que les falta para llegar a ser imagen completa de la comunión plena a la que Dios las llama (Niño, 1996, p. 211).

La misión de la Iglesia no se limita a los individuos, sino que incluye también la conversión de las ciudades. La actual realidad deshumanizada de las ciudades es un obstáculo para la vida cristiana. Hacer las ciudades más humanas es una tarea en la que deben estar presentes los cristianos (Guinda, 2002, p. 1140).

La Iglesia con un renovado ímpetu misionero debe hacer un esfuerzo para responder a los nuevos desafíos que presenta el mundo actual y concretizar la acción evangelizadora en la situación propia de la comunidad a la que va dirigida, saliendo al encuentro de aquellos ambientes que aglomeran muchísimas personas pero cuya evangelización ha sido hasta cierto punto descuidada, como ocurre en el campo universitario, en las fábricas, en torno a la clase obrera, en medio de los políticos y de los intelectuales, en el mundo de la comunicación social, en la cultura digital, etc. Para lograr esto, se hace necesaria la evangelización de la cultura o, mejor, de los forjadores de la cultura actual, y de manera especial una nueva evangelización que comience en las personas, la familia y la parroquia, para afrontar el amplio fenómeno de la secularización.

Se trata, por ende, de una evangelización cuyo contenido es el mismo de siempre, pero que debe ser novedosa en el modo como se realice para que llegue al corazón del hombre de hoy (Ruiz, 2012, p. 326).

\subsection{La ciudad interlocutora de la Iglesia}

Pablo VI (1964, n. 60) señalaba: “La Iglesia debe entrar en diálogo con el mundo en el que tiene que vivir. La Iglesia se hace Palabra. La Iglesia se hace mensaje. La Iglesia se hace coloquio". Y la razón principal es que, en el corazón de la Revelación y de la fe, el diálogo representa el cauce privilegiado por el que el misterio del Dios vivo se entrelaza con el misterio del hombre, para forjar juntos una alianza en el tiempo, para llegar a la alianza escatológica donde nunca más el diálogo será interrumpido. 
El diálogo es la acción indispensable para establecer una fecunda interlocución. Es importante definir quiénes son los sujetos dialogantes. Por un lado, la Iglesia, desde su propia naturaleza y misión, el anuncio del Evangelio. Y, por otro, las culturas, desde su pluralidad, sus autonomías e interacciones. Es necesario resaltar el encuentro de estos dos sujetos como una indispensable interlocución. Hay que señalar también que es el ingreso, en actitud de servicio, en el rico mundo de la interculturalidad. Dimensión esta que exige una inserción real en el ser social de los sujetos particulares y colectivos que producen la cultura y generar relaciones de reciprocidad (Camargo, 2009, p. 2).

La ciudad pide hoy a la Iglesia entrar en ella como entró Jesús en Jerusalén (cfr. Mt, 21, 1-11), con dolor de humanidad; si no se tiene tal actitud de Jesús, no se podrá generar otra mentalidad, el arrojo suficiente para hacer giros indispensables, la deconstrucción de imaginarios caducos y, sobre todo, no se tendrá la sensibilidad y la capacidad para comprender al ser humano de hoy; sencillamente, no será significativo. Esta nueva actitud nos la da una identidad total con el estilo de Jesús. Un paradigma pastoral urbano en fecunda creación solo será posible en la medida en que la pastoral prolongue la profecía urbana del Señor Jesús.

La actitud de Jesús profeta urbano de Jerusalén de derramar lágrimas por la ciudad (cfr. Lc 19, 41) es el punto de partida de una espiritualidad urbana capaz de lograr traducir el ser discipular y misionero en un lenguaje intercoloquial con la gran urbe.

El llanto de Jesús sobre Jerusalén no es tan solo expresión de un sentimiento, sino que es un llanto teologal y teológico. Es teologal, porque brota de la fuente misma de su experiencia de Dios. Por esto, es llanto de honda compasión, de desbordamiento misericordioso, porque ha sido asumido el proyecto del Padre. Consecuentemente, Jerusalén, la Ciudad, se le ha metido en las entrañas. Es teológico, porque manifiesta el buen uso de la reflexión sobre su fe que hace la comunidad lucana. Esta comunidad, al hacer la memoria viva de Jesús, piensa su fe y deja que las cuestiones humanas se la interroguen y desafíen. El Evangelio lucano nos entrega fielmente este gesto de Jesús porque lo ha hecho propio, porque su manera de sentir y vivir la ciudad es la misma de Jesús (Camargo, 2009, p. 6).

Hoy los comprometidos por cooperar en la construcción del Reino de Dios en la ciudad están llamados a vivir y sentir la ciudad siguiendo el ejemplo de Jesús, teniendo presente que tal construcción del Reino se hará en la medida en que se busque ampliar los espacios de la dignidad humana.

Este diálogo, esta interlocución con la ciudad, requiere ponerse, ante todo, en actitud de escucha. Antes de diseñar planes pastorales, este debe ser el imperativo ético de los discípulos urbanos: escuchar largamente, como lo hizo Jesús 
Resucitado con los caminantes dolidos de Emaús (cfr. Lc, 24, 13-24), al interesarse por su situación, al indagar su desconsuelo. Para esta escucha, se requiere entonces insertarse en los sectores humanos y sociales (Vietmeier, 2007), donde haya una actitud de solidaridad con su sed de dignificación. Estos son lugares fronterizos de la pastoral, son la Galilea de nuestras ciudades, son nuestra identidad discipular con la praxis de Jesús.

La actitud de diálogo pone a la Iglesia ante la tarea de reconocer en los problemas humanos de hoy los retos para la fe. Una misión urbana, consecuentemente, debe ser misión de la misericordia en el momento actual en que vivimos. Esta debe ser la dimensión soteriológica de la misión que se nos pide realizar. No se trata de recuperar la gente que se ha ido sin interlocución alguna, menos, un mínimo asomo de intenciones apologéticas. No se necesitan estas tácticas si lo nuestro es esta transparente comunión con el que sufre hasta las últimas consecuencias, en coherente seguimiento discipular de Jesús, el Señor de la Vida y su Buena Nueva, la misericordia hecha humanidad (Camargo, 2009, p. 8).

Otro elemento que es importante privilegiar son los tiempos y las oportunidades para crear vínculos de amistad con la gente, gastar menos energías en acciones de infraestructura física, lo que deja exhaustos, incapaces de atender la demanda de acompañamientos pacientes de las angustias y necesidades de las personas. A veces angustian y ocupan más las campañas de búsqueda de dineros para construcciones y cosas similares que se termina argumentando que a causa de la fatiga no hay tiempo ni para pensar.

Puede ponerse en evidencia un elemento de gran relevancia en la actitud interlocutora de la Iglesia para con la ciudad: la afectividad pastoral que va más allá del tradicional concepto y territorio parroquial. Conoce a fondo los vínculos sociales que instaura la gente para generar solidaridades y procesos identitarios nuevos. Los giros afectivos del lenguaje se enriquecen con estas nuevas formas de estar sociales que buscan ser visibilizadas y reconocidas. La experiencia de fe y de vida de las comunidades fundantes se forjó en la afectividad. Ejemplo de ello es toda la descarga afectiva de Pablo con sus colaboradores, expresada en el abrazo fraterno y en la calidez de su lenguaje epistolar.

La presencia de la Iglesia en la ciudad debe estar imbuida de esta fuerza vital, pues nada crece sin afectividad. En efecto, el lenguaje, en todas sus facetas, es "la morada del ser", la "casa donde habita el hombre", al decir de Heidegger. Somos todo lenguaje. ¡Qué bello, en este sentido, ser Lenguaje del Evangelio! (Camargo, 2009, p. 8).

La actitud interlocutora es la postura que más le conviene adoptar a la comunidad eclesial, no solo porque está más acorde con el proceder de Dios en la 
revelación, sino también porque obedece al estilo de relación que anhelan los hombres y las mujeres de nuestro tiempo. La relación de interlocución se funda en el reconocimiento de la igualdad y el derecho que todos tienen a la palabra.

\section{La parroquia: punto neurálgico de la Iglesia local urbana}

Hace algunos años había pastoralistas que anunciaban el final de las parroquias al constatar su inoperancia:

Ciertamente, en muchos países, la parroquia ha sido sacudida por el fenómeno de la urbanización. Algunos quizá han aceptado demasiado fácilmente que la parroquia sea considerada como superada, sino destinada a la desaparición, en beneficio de pequeñas comunidades más adaptadas y más eficaces. (Juan Pablo II, 1979, n. 67)

La parroquia fue creada por la necesidad de tener comunidades de personas que se conocieran y se ayudaran, pero también hay que anotar que ellas ejercían una función de control del individuo y el poder era centralizado en el sacerdote. Ahora bien, esta sociedad ha sido suplantada por una realidad distinta, formada de sectores independientes y secularizados (Valencia, 1998, p. 4).

Hay que reconocer que la parroquia es una presencia entre otras muchas y que parte de su responsabilidad es descubrir su vocación para hacer que el Evangelio descienda a la realidad y provoque buenas noticias en la ciudad. A ella se debe, en buena medida, la encarnación del cristianismo en las tradiciones de los pueblos y la configuración social de las ciudades. Gracias a las parroquias el éxodo rural hacia las grandes ciudades ayudó a que encontraran una integración y estabilización de estos grandes aglomerados sociales. Pero también la parroquia es una presencia contradictoria. En ella pueden encontrarse lo mejor y lo peor de la vida de la Iglesia, porque a la vez que acompaña, muchas veces propicia una incorporación a la comunidad eclesial más sociológica que verdadera, y su praxis pastoral hecha sobre todo de catequesis, sacramentos y homilías - ha sido más un factor de conservación social que fuente inspiradora de transformación de la ciudad (Díaz, 1996, pp. 207-208). La parroquia es una presencia pública que habla del carácter esencialmente público del mensaje cristiano y del interés que este tiene por hacer que la fe desarrolle estrategias para "promover la justicia social y global". La Iglesia no solo no renuncia a estar presente en la ciudad, sino que una parte esencial de su misión consiste en ayudar a configurar un orden social más humano. 
Es cierto que la ciudad es demasiado compleja para ser abordada desde un solo ángulo. El conglomerado ciudadano está hecho de espacios y estructuras que desbordan los perfiles parroquiales. En los ámbitos que están fuera de sus competencias y de sus posibilidades, como la economía, la política, la sanidad, el trabajo, etc., indirectamente, sin embargo, debe estar presente animando a los creyentes a la inserción en esos espacios de la vida ciudadana.

Si a menudo no se acierta en la tarea, es porque se desconocen cuáles son las exigencias, la naturaleza y las apuestas de la parroquia evangelizadora, que piden:

Desplazar esta hacia la vida, en una sensibilización conjuntamente a la situación concreta de las gentes, analizando con ojos evangelizadores la realidad humana cercana y mundial, desarrollando un estilo de parroquia acogedora y cálida y haciendo resonar la vida real en las celebraciones litúrgicas. (Díaz, 1996, p. 209)

La movilidad urbana ha puesto en crisis la parroquia de la ciudad, basada predominantemente en la comunidad territorial y en la fisionomía sociológica de la ciudad actual, donde las relaciones entre vecinos son frecuentemente ocasionales y superficiales, mientras que con la gente que vive lejos las relaciones son tal vez cordiales y amistosas.

Lo que une en la ciudad, por tanto, no es la geografía. Las relaciones afectivas y de interés del hombre urbano rompen con la geografía. Tienen una dimensión mucho más personal. Su "vecino" no es el que vive a su derecha o izquierda, arriba o abajo. Su "vecino" es el amigo elegido, aquel con quien entra en comunión de ideas o de intereses de cualquier tipo, viva cerca o lejos (Berstand, 1984). Este es un elemento de análisis clave a la hora de reflexionar sobre la pregunta “¿Quién es mi prójimo?". Porque la respuesta no es la más obvia ni la más lógica.

Los cristianos que viven en una misma demarcación parroquial urbana no se sienten unidos o relacionados entre sí por el hecho de ser feligreses de tal o cual parroquia. Las parroquias de la gran ciudad, por tanto, no pueden basarse en lazos de vecindad. No son "comunidades", sino más bien "colectividades" de personas que entienden la ciudad como un todo orgánico, diversificado en múltiples grupos sociales que uno elige cuando y como quiere.

El hombre actual, a consecuencia de la moderna separación entre familia y mundo del trabajo, vive en diferentes ámbitos y contextos, y tiene que ser abordado en modo adecuado y diferenciado. Una exigencia unilateral de la parroquia resulta obsoleta por la movilidad actual, especialmente en los domingos y días festivos, y por la importancia creciente del tiempo libre. 
En la parroquia urbana, la persona del sacerdote no ha pasado de moda, pero su figura no será del hombre autoritario o centralista, sino del animador y coordinador de los carismas. Será capaz de promover a los laicos, formar grupos de trabajo con ellos y trabajar en un clima de corresponsabilidad. Tendrá que saber relacionarse con personas de todos los niveles y ser personas de diálogo con la pluralidad propia de la ciudad. La Iglesia en la ciudad debe ser capaz de promover a los laicos como protagonistas de la pastoral urbana.

Una parroquia urbana tiene que ser solidaria con el sufrimiento de la población. Los cristianos no solo acuden a ella para buscar cualquier cosa, sino para convertirse ellos mismos en testigos y misioneros en la gran ciudad (Valencia, 1998, pp. 42-44).

La parroquia no es en la mayoría de los casos comunidad, ya que entre los feligreses están casi ausentes las relaciones interpersonales, sobre todo en la urbe. El habitante de la ciudad distingue entre vida pública y vida privada: para él la religión es parte de la segunda. Nace una religión de fe personal donde el individuo es quien se siente responsable frente a alguien. Es alérgico al autoritarismo del clero, reacciona con la abstención y la ausencia. Para él la autoridad es solo sinónimo de competencia. En ella existen personas que si son acompañadas, estimuladas y coordinadas, serán capaces de realizar un magnífico trabajo de evangelización.

Es necesario plantearse la pregunta si vale la pena sostener la parroquia urbana y qué tipo de parroquia reclaman el hombre y la mujer urbanos (Bravo, 1999, pp. 73-75).

Es necesario ser conscientes de que una parroquia que se quiera mantener dentro de los muros o los límites de su territorio está destinada a permanecer en el aislamiento, o bien a desaparecer. Al hombre de la ciudad, por tanto, no se le puede encasillar en unos estrictos límites parroquiales de tipo territorial (Berstand, 1984, pp. 661-662).

La parroquia urbana ha de ser pluralista dado el pluralismo de la propia gente que la conforma. Los elementos demográficos, culturales, intelectuales, profesionales y laborales hacen que exista un pluralismo. Por otro lado, la diversidad de estatus, la diversidad en los niveles de participación en la propia parroquia (alejados, ocasionales, habituales, comprometidos) y la diversidad de ideología (en las personas o en los grupos parroquiales) están motivando un pluralismo. El pluralismo es positivo y enriquecedor. El pluralismo que existe en el barrio, si es recogido en las programaciones parroquiales, puede convertirse en un pluralismo rico y fértil, siempre y cuando haya un proyecto pastoral claro que lo sustente y lo conexione. De otro modo, el pluralismo se hace indiscriminado, 
desorganizado, y más que favorecer la formación de una auténtica comunidad, lleva a la disgregación o, incluso, al enfrentamiento de grupos.

La parroquia, para la mayoría de los bautizados, es el lugar y el ámbito en donde lo eclesial se hace accesible y experimentable. Para la mayoría de los no creyentes, es en gran medida la referencia concreta que puede tener la Iglesia.

Debe concebirse la parroquia no como un territorio sino principalmente, como sucede con la definición de Iglesia particular, una comunidad. La parroquia es célula viva de la Iglesia diocesana y que tiene la misma triple misión que le ha sido encomendada al Pueblo de Dios: profética y de evangelización, sacerdotal y de celebración, real y de compromiso. La parroquia, concebida como comunidad de comunidades, se sitúa en la óptica de la unidad, comunión, corresponsabilidad y evangelización (Berzosa, 2000, pp. 847-848).

Las parroquias urbanas deben ser más bien como centros abiertos, capaces de aglutinar grupos de talla humana, que en pequeños grupos evangelizadores van allá donde la gente se encuentra; tendrá futuro, porque logrará superar, dejar atrás una pastoral de cristiandad, de mantenimiento, de conservación, para dar paso a una pastoral de la misión, de crecimiento, que planifica su trabajo, no en función del "siempre se ha hecho así" o de las estructuras y tareas existentes, sino de la realidad circunstante, de la personalización de la fe de los individuos y de la transformación de los ambientes (Berstand, 1984, pp. 662-663).

En una planificación pastoral, habrá que buscar un equilibrio correcto entre la pastoral parroquial y la pastoral extraparroquial. Para una pastoral urbana, es fundamental la parroquia territorial en el espacio vital del barrio. Tiene grupos y los integra. Se siente especialmente obligada con las familias jóvenes, tiene unos límites traspasables y tolera los movimientos migratorios de los fieles. Su tarea primaria es iniciar contactos y establecer relaciones. La Iglesia y sus comunidades aparecen como lugar de saludo, de acogida. Aquí aparece el problema del contacto. El distanciamiento de algunas familias jóvenes es, muchas veces, un problema de contacto, más que un problema de fe. Una parroquia que no se esfuerza por establecer contactos no responde a lo que exige una gran ciudad.

No hay que poner en duda la prioridad de la parroquia; pero, si se considera la dimensión misionera, la pastoral extraparroquial adquiere una importancia considerable (Guinda, 2002, p. 1143).

Una cuestión crucial se pone a la parroquia: ¿será posible crear otros estilos de parroquia (por ejemplo, sectorial, personal, ambiental, solidaria con otras, encomendada a diáconos, ministros laicos, religiosas, etc.)?, ¿existe la conciencia de que al tocar la parroquia se tocará inevitablemente la figura del párroco tradicional y la misma estructura organizativa de la Iglesia diocesana? 
En continuidad con lo anterior, cabe mencionar a modo de ejemplo una alternativa pastoral atípica en el universo atípico de la urbe: la Iglesia de la casa (Merlos, 2007, pp. 332-333).

Cabe aclarar cuál es la diferencia que Merlos (2007) establece entre lo típico y lo atípico, entendiéndose como dos categorías existenciales que permiten situarse en el entorno y actuar con actitud pasiva o conformista o con actitud dinámica y creativa. Lo típico se entiende como un molde, huella, marca o modelo que reproduce un determinado número de realidades de la misma naturaleza. Lo típico, por tanto, sería la realidad reconocida, incuestionable y comúnmente aceptada, que se ajusta a parámetros habituales claramente establecidos y se desenvuelve con reglas perfectamente ordenadas e indiscutibles. Lo típico suele emparentarse con la herencia, los usos y las costumbres, las formas inflexibles que regulan la vida y los comportamientos. Lo atípico, por el contrario, sería la realidad que, sin perder la relación con su grupo de referencia vital, escapa a las características habituales que la definen, y adquieren por eso mismo un perfil único, original e irreductible a las formas y reglas tradicionales comúnmente aceptadas. Lo atípico es lo inédito, lo impredecible. La ciudad genera ciertamente toda clase de expresiones típicas comunes a todas (movilidad constante, anonimato, centralismo, esclavitud del tiempo, contraste social, exclusión, conflicto, las mayorías vulnerables), pero, al mismo tiempo, propicia sin cesar expresiones atípicas que por su novedosa irrupción llevan a vivir la urbe como una experiencia continua de sorpresa, desconcierto y turbación, debido precisamente a lo impredecible de su devenir (modas inéditas, formas populares e impensables de organización, esoterismos, conductas exóticas, formas ingeniosas de subsistencia). La ciudad puede interpretarse con parámetros que inciden en su "tipicidad", pero también puede hacerlo desde aquellos factores que configuran su "atipicidad".

Por consiguiente, una de las prácticas pastorales que nace de la intuición pastoral, y que poco a poco encuentra su fundamentación teológica, es reunirse en grupo en medio de un mundo que cada día se divide y se aísla más. La Iglesia de la casa, en cuanto alternativa atípica de la pastoral urbana, se nos propone hoy en unos términos que inducen a tomar posturas pastorales congruentes. Se afirma de ella que es un espacio concreto, normalmente pequeño, pero perteneciente a un territorio común; conlleva una relación personalizada basada en el vecindario; se identifica con símbolos sencillos y cercanos; ejercita la espontaneidad en el diálogo; escucha comunitariamente la palabra de Dios; y realiza una búsqueda familiar de la trascendencia y del misterio como fuentes que dan sentido a la vida y fortalezcan para la lucha diaria (Merlos, 2007, pp. 339-340). 


\section{Conclusión}

Una Iglesia en estado de misión debe estar organizada en función del mundo exterior, no en función de sí misma. En primer lugar, la Iglesia debe mirar la ciudad como conjunto. Al frente está un obispo con un consejo pastoral que no administra las parroquias, sino que trata de entender la ciudad, de escoger los puntos de presencia y elaborar los mensajes cristianos para la ciudad en cada momento de su historia presente. En el centro de la ciudad, está el corazón de la Iglesia local, que trata de comprender espiritualmente las señales de los tiempos en una ciudad determinada.

La ciudad hoy no solo es espacio geográfico o acontecimiento históricocultural, sino nexo de complejas relaciones humanas y estructurales, una complejidad de fuerzas y poder. Sin duda, el desafío en la ciudad está en humanizar la ciudad y sus acciones, lo que significa promover la persona humana y urbana (Davey, 2003, p. 10).

Aparecida nos anima a evangelizar la ciudad actual con alegría y valentía (cfr. Consejo Episcopal Latinoamericano [Celam], 2008a, n. 517). La fe nos enseña que Dios vive en la ciudad en medio de sus alegrías, anhelos y esperanzas, así como en sus dolores y sufrimientos. Las sombras que en ella se viven no pueden impedir que contemplemos al Dios de la vida en el contexto urbano.

Las ciudades son lugares de libertad y oportunidad, y en ellas las personas tienen la posibilidad de conocer a más personas, interactuar y convivir con ellas. En las ciudades, es posible experimentar vínculos de fraternidad, solidaridad y universalidad. En ellas el ser humano es llamado constantemente a caminar siempre más al encuentro del otro, convivir con el diferente, aceptarlo y ser aceptado por él. La Iglesia debe acampar en la ciudad como la tienda de campaña que Jesús ha instalado entre los hombres, estando al servicio y realización de la ciudad a través de la proclamación y vivencia de la Palabra, de la celebración de la liturgia y de la comunión fraterna; ella debe ser fermento en la ciudad actual (cfr. Celam, 2008a, n. 514).

Es importante despertar en nuestros agentes de pastoral la conciencia misionera en este momento para nuestra ciudad y sentirnos en verdadero estado de misión y discípulos llamados para anunciar el Evangelio en esta nueva época (Celam, 2008b, p. 13); apostarle en mayor modo a la creación y el fortalecimiento de relaciones interpersonales fraternales, sólidas y verdaderas, e integrarlas a nivel parroquial y diocesano; integrar e inculturar elementos propios de la vida cristiana en la vida de la ciudad, y abrirse a nuevas experiencias, estilos, 
lenguajes, que puedan encarnar el Evangelio en la ciudad; la presencia de la Iglesia debe garantizarse en la ciudad en los distintos sectores urbanos y humanos. Es importante descentrar la acción eclesial e integrar centro y periferia, para lo que el papel de los discípulos laicos misioneros es fundamental, ya que ellos con una formación adecuada, su presencia, acción y misión, serán signo profético y farol de luz para la ciudad.

\section{Referencias}

Álvarez, E. Y. (1988). Evangelización en la gran ciudad: actitudes fundamentales. Teología y Catequesis, 25, 27-49.

Berstand, J. (1984). Desafíos de la nueva realidad urbana a la parroquia. Sal Terrae, 72(9), 665-674.

Berzosa Martínez, R. (2000). Parroquia. En V. M. Pedrosa, J. Sastre y R. Berzosa (dirs.), Diccionario de pastoral y evangelización (pp. 847-851). Burgos, España: Monte Carmelo. Recuperado de https://mercaba.org/Pastoral/INDICE_DE_PASTORAL. htm

Bravo, B. (1999). La Iglesia en la ciudad. Ciudad de México, México: Dabar.

Camargo Cortés, A. y Mancera Casas, J. A. (4 de febrero de 2007). Búsqueda de una teología pastoral. Recuperado de https://pastoralurbanabogota.blogspot. com/2010/04/en-busqueda-de-una-teologia-pastoral.html

Camargo Cortés, A. E. (2009). La Iglesia evangelizadora de la ciudad: propuestas pastorales. Trabajo presentado en Simposio sobre Pastoral Urbana: La Iglesia en la ciudad, organizado por la Arquidiócesis de Cali.

Caramurú, R. (1967). La Iglesia al servicio de la ciudad. Barcelona, España: Nova Terra.

Comblin, J. (1968). Théologie de la ville. París, Francia: Éditions universitaires.

Consejo Episcopal Latinoamericano (1982). Pastoral y parroquia en la ciudad. Bogotá, Colombia: Autor.

Concilio Vaticano II (1995). Documentos completos. Bogotá, Colombia: San Pablo.

Consejo Episcopal Latinoamericano (2008a). V Conferencia General del Episcopado Latinoamericano y del Caribe. Bogotá, Colombia: Autor.

Consejo Episcopal Latinoamericano (2008b). La misión continental para una iglesia misionera. Bogotá, Colombia: Autor.

Davey, A. (2001). Urban Christianity and global order: Theological resources for an urban future. Londres, RU: British Library.

Davey, A. (2003). Cristianismo urbano y evangelización. Bilbao, España: Sal Terrae. 
Díaz Marcos, C. (1996). La parroquia una presencia de la Iglesia en la ciudad. Sal Terrae, 83/3(988), 207-218.

Dorado, A. G. (1983). Una Iglesia más evangelizadora en las grandes ciudades. Medellin, 90.

Ferrari, G. (2004). Le citta luogo della missione. Testimoni, 12, 7-10. Recuperado de http://data.over-blog-kiwi.com/0/51/25/32/20181030/ob_29e783_gabriele-ferraris-x-le-citta-l.pdf

Frosini, G. (2007). Babele o Gerusalemme? Teologia delle realtà terrestri: I. La città. Bolonia, Italia: EDB.

Gaudium et spes (1965). Recuperado de http://www.vatican.va/archive/hist_councils/ii_vatican_council/documents/vat-ii_const_19651207_gaudium-et-spes_ sp.html

Guinda, F. J. (2002). Pastoral urbana. En C. Floristán (dir.), Nuevo diccionario de pastoral (pp. 1139-1146). Madrid, España: San Pablo.

Juan Pablo II (1979). Catechesi tradendae. Recuperado de http://w2.vatican.va/content/ john-paul-ii/es/apost_exhortations/documents/hf_jp-ii_exh_16101979_catechesitradendae.html

Juan Pablo II (1981). Laborem exercens. Recuperado de http://w2.vatican.va/content/ john-paul-ii/es/encyclicals/documents/hf_jp-ii_enc_14091981_laborem-exercens. html

Juan Pablo II. (1985) Discorso di Giovanni Paolo II ai partecipanti al VI Simposio del Consiglio Delle Conferenze Episcopali D'Europa. Recuperado de https://w2.vatican.va/content/john-paul-ii/it/speeches/1985/october/documents/hf_jp-ii_spe_19851011_ partecipanti-simposio.html

Lumen gentium. (1964). Recuperado de http://www.vatican.va/archive/hist_councils/ii_vatican_council/documents/vat-ii_const_19641121_lumen-gentium_ sp.html

Marafioti, D. (2012). La categoria ecclesiologica di citta nel magistero recente. Rassegna Teologica, 2, 232-233.

Martinic, M. B. (1993). Iglesia y ciudad en América Latina: análisis de una práctica evangelizadora y evaluación de sus alcances eclesiológicos. Roma, Italia: Pontificia Universita Salesiana.

Medina Arellano, J. A. (2011). La acción pastoral en la ciudad: desde la realidad pastoral hispana de la Iglesia católica en los Estados Unidos de América. Salamanca, España: Universidad Pontificia de Salamanca.

Merlos, F. (2002). Pastoral en crecimiento: fuerzas y debilidades, cuestionamientos y urgencias. Ciudad de México, México: Palabra.

Merlos, F. (2007). Pastoral atípica. En J. J. Legorreta (dir.), 10 palabras clave sobre pastoral urbana (pp. 307-343). Estella, España: Verbo Divino. 
Niño, F. (1996). La Iglesia en la ciudad: el fenómeno de las grandes ciudades en América Latina como problema teológico y como desafío pastoral. Roma, Italia: Pontificia Universidad Gregoriana.

Pablo VI. (1964). Eclesiam suam. Recuperado de http://w2.vatican.va/content/paul-vi/ es/encyclicals/documents/hf_p-vi_enc_06081964_ecclesiam.html

Peresson Tonelli, M. (2007). La iniciación cristiana en la ciudad desde la pedagogía de Jesús: cómo acceder a la fe en la ciudad. Trabajo presentado en Congreso de Teología y Pastoral. Recuperado de https://mercaba.org/ARTICULOS/B/Bogota_00_cartel_ponencias.htm

Ruiz Arenas, O. (2012). Dimensión misionera de la nueva evangelización. Misiones Extranjeras: Revista de Misionología, 248-249, 317-334.

Tonna, B. (1978). Un vangelo per la cittá: il passaggio della missione rurale alla misione urbana nel terzo mondo. Milán, Italia: EMI.

Uribe, C. E. (1990). Eclesiología para la misión. Bogotá, Colombia: OMP.

Valencia, A. F. (1998). Acercamiento sociopastorales a la urbe: parroquia, mundo urbano y comunidad. Ciudad de México, México: Dabar.

Vietmeier, A. (2007). Sujetos urbanos y evangelizacion. En J. de J. Legorreta (dir.), 10 palabras clave sobre pastoral urbana (pp. 143-169). Estella, España: Verbo Divino.

Zulehner, P. M. (1992). Teologia pastorale. 1, Pastorale fondamentale: la chiesa fra compito e attesa. Brescia, Italia: Queriniana. 